\title{
METODOLOGIAS ATIVAS E NOVAS COMPETENCIAS DOCENTES: UMA EXPERIÊNCIA DE PRODUÇÃO DE TEXTOS IMAGÉTICOS NO MEIO DIGITAL
}

\author{
METODOLOGÍAS ACTIVAS Y NUEVAS COMPETENCIAS DOCENTES: UNA \\ EXPERIENCIA DE PRODUCCIÓN DE TEXTOS-IMÁGENES EN AMBIENTE \\ DIGITAL
}

\author{
ACTIVE METHODOLOGIES AND NEW TEACHING COMPETENCES: AN \\ EXPERIENCE OF IMAGING TEXT PRODUCTION WITHIN THE DIGITAL MEDIA
}

\author{
Roberta CAIADO ${ }^{1}$ \\ Renata Fonseca Lima da FONTE ${ }^{2}$ \\ Isabela Barbosa do Rêgo BARROS ${ }^{3}$
}

RESUMO: Respaldado nas metodologias ativas de ensino, este artigo apresenta o relato de uma experiência pedagógica - produção de textos imagéticos - desenvolvida em tecnologia digital móvel, proposta para professores em formação inicial. Metodologicamente, realizamos um estudo de caso com licenciandos em Letras de uma Universidade particular localizada no estado de Pernambuco. Concluímos que os docentes em formação ampliam suas competências quando utilizam caminhos autônomos que os façam avançar em conhecimento, competências socioemocionais e em novos gestos pedagógicos.

PALAVRAS-CHAVE: Formação. Professor. Metodologias ativas. Tecnologia digital.

RESUMEN: Respaldado en las metodologías activas de enseñanza, este artículo presenta el relato de una experiencia pedagógica - producción de textos-imágenes - desarrollada en tecnología digital mueble, propuesta para profesores en formación inicial. Metodológicamente, realizamos un estudio de caso, con estudiantes de profesorado en Letras de uma universidad privada ubicada em el estado de Pernambuco. Concluimos que los docentes en formación amplían sus competencias cuando utilizan caminos autónomos que os hagan avanzar en conocimiento, competencias socioemocionales y en nuevos gestos pedagógicos.

PALABRAS CLAVE: Formación. Docente. Metodologías activas. Tecnología digital.

${ }^{1}$ Universidade Católica de Pernambuco (UNICAP), Recife - PE - Brasil. Coordenadora da Pós-graduação Stricto Sensu da UNICAP, Professora e Pesquisadora do Programa de Pós-graduação em Ciências da Linguagem, Professora do Curso de Letras Centro de Teologia e Ciências Humanas. Doutorado em Educação (UFPE). ORCID: https://orcid.org/0000-0002-4444-774X. E-mail: roberta.caiado@unicap.br

${ }^{2}$ Universidade Católica de Pernambuco (UNICAP), Recife - PE - Brasil. Professora e Pesquisadora do Programa de Pós-graduação em Ciências da Linguagem, Professora do Curso de Letras Centro de Teologia e Ciências Humanas. Doutorado em Linguística (UFPB). ORCID: https://orcid.org/0000-0002-3407-4409. E-mail: renata.fonte@unicap.br

${ }^{3}$ Universidade Católica de Pernambuco (UNICAP), Recife - PE - Brasil. Coordenadora do Programa de Pósgraduação em Ciências da Linguagem, Professora e Pesquisadora do Programa de Pós-graduação em Ciências da Linguagem, Professora do Curso de Letras Centro de Teologia e Ciências Humanas. Doutorado em Letras (UFPB). ORCID: https://orcid.org/0000-0002-0123-7670.E-mail: isabela.barros@unicap.br

RIAEE - Revista Ibero-Americana de Estudos em Educação, Araraquara, v. 16, n. 4, p. 2682-2700, out./dez. 2021. e-ISSN: 1982-5587 DOI: https://doi.org/10.21723/riaee.v16i4.14043 
ABSTRACT: Supported by active teaching methodologies, this article presents an account of a pedagogical experience - production of imagery texts - developed in mobile digital technology, proposed for initial teachers under formation. Methodologically, we carried out a case study, with teaching degree students in Languages and Literature of a private university located in the state of Pernambuco. We conclude that teachers under formation expand their skills when they use autonomous paths which make them advance towards knowledge, socioemotional skills and in new pedagogical gestures.

KEYWORDS: Formation. Teacher. Active methodologies. Digital technology.

\section{Introdução}

A educação do século XXI exige ressignificações acerca de quem são e que lugar ocupam os agentes (docente, discente e comunidade escolar) no novo cenário de aprendizagem entrelaçado pelas Tecnologias Digitais da Informação e Comunicação (TDIC). Novos conceitos são incorporados ao que nos acostumamos definir como sala de aula em perspectiva tradicional ou clássica: espaço fechado para aprendizagem, com apenas uma saída ou entrada, onde os agentes ocupam posições organizadas e preestabelecidas, formando/constituindo o que compreendemos por turma/série/ano. No novo paradigma educacional, a sala de aula passa a ser o mundo, com várias possibilidades de arranjos e caminhos a serem percorridos durante o processo de aprendizagem.

Porém, ainda há uma tendência de as escolas trabalharem massivamente a produção de textos verbais-escritos, no modelo educacional dos séculos XIX e XX, promovendo o letramento impresso em detrimento do letramento digital, que vai requerer letramentos contemporâneos, incluindo o letramento visual, o qual incorpora práticas sociais de produzir e ler textos imagéticos. Diante dessa tendência escolar, os discentes apresentam dificuldades para compreender e produzir textos, comumente encontrados em livros didáticos e nas provas do Exame Nacional do Ensino Médio - Enem, que dependem da interlocução entre imagem e verbo (CAIADO, 2011). 
O fortalecimento de um paradigma educacional colaborativo, que trabalha a capacidade de associar o conhecimento linguístico tradicional, centrado no texto verbalescrito, com o conhecimento visual, é possível a partir de uma abordagem mais centrada na imagem em detrimento de uma abordagem voltada apenas para o texto verbal, conforme afirma Almeida (2011). Desse modo, promover o letramento visual em contextos de sala de aula contribui para que docente e discente coatuem de forma colaborativa no processo de ensino e aprendizagem e ainda promove a leitura e a produção de textos contemporâneos de forma mais crítica e reflexiva.

A partir de práticas de produção de texto, este artigo apresenta o relato de uma experiência pedagógica - produção de textos imagéticos - desenvolvida em Tecnologia Digital Móvel (TDM), a partir da aprendizagem baseada em projetos, proposta para professores em formação inicial de um curso de Letras de uma Universidade particular localizada no estado de Pernambuco. De forma a alcançar este objetivo, discentes do último período do curso de Letras, professores em formação inicial, foram desafiados a desenvolver um projeto, relacionado à produção textual imagética, realizado em Tecnologia Digital Móvel.

Desse modo, este artigo se inicia discutindo a proposta atual de metodologias ativas para a educação, focando na aprendizagem baseada em projetos. Em seguida, apresentamos o perfil e as competências dos professores para uma prática pedagógica em ambientes digitais. Finalizamos com a metodologia e o relato da experiência vivenciada, na sequência as considerações e as referências.

\section{Metodologias Ativas: Aprendizagem Baseada em Projetos}

Procurando entender como as pessoas adquirem o conhecimento, Bransford, Brown e Cocking (2000) apontam indicadores que alicerçam as propostas que norteiam o ensino ativo pensado a partir do estudante e para o estudante. A saber: 1) Há nos sujeitos uma predisposição precoce para aprender sobre algumas coisas, mas não outras; 2) Os sujeitos desenvolvem competências estratégicas e metacognitivas para a aprendizagem; 3) O contato com outros sujeitos desempenha papel importante na busca pelo conhecimento. Esses indicadores respondem ao que preconizam as metodologias ativas: i) Respeito ao projeto individual e de vida de acordo com o tempo e a maturidade do discente; ii) A busca pela solução dos desafios propostos fomenta a aprendizagem; iii) A relação com os pares e com o mundo por meio da web incentiva a ampliação do conhecimento. 
De modo objetivo, as metodologias ativas correspondem ao paradigma educacional centrado no discente, contrário às aulas apenas instrucionais focadas no docente. Nesse último modelo, de acordo com Valente e Almeida (2014, p. 36), “o espaço formal da sala de aula tem estreita relação com a visão positivista, [...] fundada sobre uma ilusão de estabilidade do contexto advinda do local fixo, dos recursos comuns, do professor e de um currículo moldado previamente".

Diferentemente, no modelo de aprendizagem ativo, o discente é o protagonista na aquisição de conhecimento. Ele aprende solucionando os desafios propostos, interagindo com os outros agentes (colegas de turma/classe e professores), confrontando suas ideias e compartilhando experiências e informações. A construção do conhecimento ocorre de forma personalizada nas ações realizadas a partir de reflexões teóricas e o compartilhamento de ideias, respeitando-se os tempos individuais e coletivos e envolvendo projetos pessoais de vida e de aprendizagem.

Essas ideias já foram expostas por Paulo Freire (2011), ao defender que a aprendizagem é impulsionada pela superação dos desafios, pelas descobertas advindas de vivências e conhecimentos prévios e pela autonomia do ser educando.

Para Moran (2018), toda aprendizagem, em seu conjunto, é ativa de algum modo, pois exige do discente e do docente formas diferentes de: mobilização interna e externa, motivação, seleção, interpretação, comparação, avaliação e aplicação. A habilidade em usar a tecnologia digital, em especial a móvel, é fundamental para uma educação plena, por envolver as competências mencionadas por Moran e, ainda, segundo Caiado, Fonte e Barros (2018), permitir a ubiquidade na construção do conhecimento, a interatividade, o uso de diferentes linguagens, a personalização, o planejamento e a reelaboração em seu agir pedagógico.

Como uma das possibilidades estratégicas das metodologias ativas, a Aprendizagem Baseada em Projetos (ABP ou ABPj), segundo Moran (2018, p. 16),

[...] é uma metodologia de aprendizagem em que os alunos se envolvem com tarefas e desafios para resolver um problema ou desenvolver um projeto que tenha ligação com sua vida fora da sala de aula. No processo, eles lidam com questões interdisciplinares, tomam decisões e agem sozinhos e em equipe. Por meio dos projetos, são trabalhadas também suas habilidades de pensamento crítico e criativo e a percepção de que existem várias maneiras de se realizar uma tarefa, competências tidas como necessárias para o século XXI. ${ }^{4}$ Os alunos são avaliados de acordo com o desempenho durante as atividades e na entrega dos projetos (MORAN, 2018, p. 16). [Nota nossa]

4 Aprender a conhecer, aprender a fazer, aprender a (con)viver e aprender a ser são as quatro competências para o aprendizado no mundo contemporâneo. 
Diante de um problema âncora ${ }^{5}$ os discentes se veem estimulados a desenvolver competências e habilidades que atendam às provocações apresentadas pelo professor, mas que, naturalmente, também poderiam ser necessárias para atender aos desafios impostos em uma situação profissional. Desse modo, pode haver mais de uma solução aceitável para o problema de acordo com a percepção e a necessidade individual ou do grupo.

Viabilizando o encaminhamento para a solução do problema, os envolvidos com a execução do projeto planejam e organizam uma série de tarefas que, de acordo com Bender (2015), são variáveis, mas, geralmente, incluem: realizar brainstorming ${ }^{6}$; selecionar os descritores norteadores para a coleta de informações; compartilhar responsabilidades e tarefas; levantar o estado da arte sobre o tema; pesquisar para solucionar o problema; sintetizar as informações coletadas; definir cooperativamente os caminhos a serem seguidos com base nas informações colhidas e determinar outras informações relevantes; desenvolver produtos que possibilitem aos discentes socializar os resultados.

É preciso ter cuidado, no entanto, pois, segundo o mesmo autor, nem todo projeto proposto se configura como uma abordagem da ABP. A atividade deve se caracterizar como pessoalmente significativa para os estudantes, para que gere neles o máximo de envolvimento na resolução do problema, devem estar claras as especificações sobre os papéis dos discentes dentro do contexto do projeto e partir de uma questão altamente motivadora por estar relacionada ao mundo real.

De acordo com Krajcik e Blumenfeld (2005), Bender (2015) e Cunha et al. (2019), a ABPj privilegia o desenvolvimento de competências desejadas para uma metodologia de ensino e aprendizagem efetivas, a saber: independência, responsabilidade e disciplina. Bem como promove as capacidades de: comunicar, negociar e colaborar, necessárias ao cidadão do século XXI.

Neste sentido, na próxima seção, enfocaremos o perfil e as competências necessárias aos professores para o trabalho com as TDIC.

$5 \mathrm{O}$ termo âncora é utilizado como metáfora no sentido de ancoragem, para fundamentar o ensino em um cenário que retrata a realidade (BENDER, 2015).

6 Planejamento do projeto, em que a meta é produzir o máximo de ideais para a resolução das tarefas, sem que, inicialmente, seja descartada alguma informação. Em alguns casos, esse processo deve ser ensinado ao aluno, tendo em vista a dificuldade em lidar com os diferentes pontos de vista (BENDER, 2015).

RIAEE - Revista Ibero-Americana de Estudos em Educação, Araraquara, v. 16, n. 4, p. 2682-2700, out./dez. 2021. e-ISSN: 1982-5587 


\section{Perfil e competências dos professores em ambientes digitais}

Os docentes, que são agentes mediadores na transposição dos saberes, deverão desenvolver competências que atendam às demandas do que se propõe a educação do século XXI, respaldadas nas metodologias ativas que requerem o uso de tecnologias digitais, em especial as Tecnologias Digitais Móveis (TDM), diretamente correlacionadas à aprendizagem móvel, $m$-learning, na escola.

[...] m-learning é a aprendizagem que acontece a partir das práticas sociais, culturais, acadêmicas e digitais dos sujeitos, em dispositivos móveis (smartphones, tablets, notebooks, dentre outros), com base nos princípios de interatividade, mobilidade, portabilidade, multimodalidade propiciados pela integração multimídia presente e, acessível, em tecnologia móvel. (CAIADO; LEFFA, 2017, p. 112)

Assim, segundo os autores, a aprendizagem móvel/m-learning é um meio multimídia e multifuncional de ensino e de aprendizagem que pode ajudar e até mesmo influenciar as práticas pedagógicas escolares, dentro do que propõem as metodologias ativas. Neste sentido, afirmamos que as TDM surtem efeitos positivos para o ensino e para a aprendizagem, pois seu uso revela uma gama de características desencadeadoras de processos mentais favoráveis à apreensão/ressignificação/reelaboração/redescrição do conhecimento.

Entendemos que novos cenários educativos podem surgir a partir do uso pedagógico das TDM, mais colaborativos e caracterizados: pela mobilidade do estudante e da aprendizagem; pela portabilidade; pela possibilidade de interação em diferentes contextos, promovendo o desenvolvimento das competências necessárias aos letrados digitais do séc. XXI. Dentre elas, destacamos: a autonomia do docente/discente que o leva a ressignificações, a reelaborações e a transgressões intencionais; a auto-organização entendida aqui como construção do conhecimento personalizado, individual e coletivo; e o gerenciamento do tempo-espaço no sentido da ubiquidade propiciada pelas TDM.

Acreditamos, assim como Bonilla (2005), que o docente precisa entender que a compreensão das especificidades das tecnologias vai além de sua funcionalidade e execução, sendo capaz de incorporá-la no contexto contemporâneo, fazendo a leitura de sua linguagem a partir de um novo modo de ser, pensar e agir. Se queremos formar novos seres pensantes e atuantes, considerando docentes comprometidos com um ensino diferenciado, autônomo, inquietante e construtivo, a partir de novas metodologias, as ativas, precisamos formá-los para 
tal fim, refletindo sobre relevantes questões impostas pela nova sociedade digital ${ }^{7}$.

Eles devem, antes de tudo, compreender o porquê do uso das tecnologias digitais na escola - em favor de processos de ensino e aprendizagem significativos -, desmistificando críticas sobre a incorporação pedagógica das TDIC no universo escolar e refletir sobre como as TDIC poderiam se tornar meio de ensino e aprendizagem na disciplina que ministram e não somente um recurso didático.

Corroboramos com as ideias de Caiado (2011), que propõe que as tecnologias digitais da informação e comunicação são meio de aprendizagem, meio carregado de conteúdo que exigirá o desenvolvimento de novas competências, favorecendo o letramento digital ${ }^{8}$ dos discentes e docentes, ensejando sua inclusão no projeto político pedagógico da escola. Entendemos novas competências, assim como propõe Pérez Gómez (2015, p. 74): “[...] sistemas complexos, pessoais, de compreensão e de atuação, ou seja, combinações pessoais de conhecimentos, habilidades, emoções, atitudes e valores". Acreditamos, conforme o autor, que essas novas competências, especialmente para o ensino com TDIC, são requeridas no trabalho a partir de metodologias ativas e "envolvem a capacidade e o desejo de compreender, analisar, propor, desenvolver e avaliar" (PÉREZ GÓMEZ, 2015, p. 74).

As novas competências exigirão a formação de professores com perfil de mediadores, que saibam mais orientar do que fazer, escutar do que falar, calar do que ministrar, que se preocupem com a resolução de problemas reais e concretos, preparados para repensar tempos, espaços, currículos, projetos político pedagógicos, ressignificando conceitos e ações, incluindo-se aí, também: a prática docente e o entendimento das TDIC, implementando mudanças, o que desafia as instituições de ensino superior na formação destes profissionais.

7 “Nova sociedade digital” é uma expressão utilizada por Pérez Gómez (2015, p. 15) no livro de sua autoria: Educação na Era Digital: a Escola Educativa.

8 Segundo Xavier (2005, p. 135), "O letramento digital implica realizar práticas de leitura e de escrita diferentes das formas tradicionais de letramento e alfabetização. Ser letrado digital pressupõe assumir mudanças nos modos de ler e escrever os códigos e sinais verbais e não verbais, como imagens e desenhos, se compararmos às formas de leitura e escrita feitas no livro, até porque o suporte sobre o qual estão os textos digitais é a tela, também digital".

RIAEE - Revista Ibero-Americana de Estudos em Educação, Araraquara, v. 16, n. 4, p. 2682-2700, out./dez. 2021. e-ISSN: 1982-5587 
Assim, a partir da compreensão proposta por Mauri e Onrubia (2010) sobre o estado das competências que os docentes deveriam adquirir para conseguir integrar as TDIC à educação, às suas práticas pedagógicas, elaboramos o Quadro 1. Ele nos dá uma visão globalizante das diferentes concepções do processo de ensino e aprendizagem com as TDIC, relacionada ao papel e às competências necessárias ao professor. Ele sintetiza o processo de ensino e aprendizagem mediado pelas TDIC a partir de três âmbitos: i) Concepção do Processo de Ensino e Aprendizagem mediado pelas TDIC, ii) Perfil/papel do Professor, iii) Competências a serem desenvolvidas nos professores.

Entendendo que o perfil do professor advém da concepção do processo de ensino e aprendizagem mediados pelas TDIC, temos o seguinte: (i) concepção centrada na dimensão tecnológica, na qual o docente domina as tecnologias no sentido proposto por Balacheff (1994), sendo um experimentador que escolhe, planeja, propõe e faz acontecer, instaura a atividade; (ii) concepção centrada no acesso, compreensão e produção da informação que exigiria um docente que incentiva uma postura crítica por parte do discente, intercedendo nos processos de busca, compreensão, avaliação e repasse da informação em rede, na rede; (iii) concepção centrada na construção do conhecimento que preconiza um docente mediador, que acompanha e cede o controle do processo de ensino e aprendizagem ao discente, utilizando a tecnologia digital para criar atividades que tenham como resultado a reorganização de suas funções cognitivas; (iv) concepção centrada em metodologias ativas, na qual o professor é um designer, um artista, que trabalha com valores, emoções, habilidades, gerenciamento da autonomia, do tempo, do espaço, em função do desenvolvimento de posturas críticas e ativas por parte do discente, enfim, um arquiteto de problemas reais.

Quadro 1 - Perfil e Competências dos Professores em Processos de Ensino Mediados pelas TDIC

\begin{tabular}{|c|l|l|}
\hline $\begin{array}{c}\text { Concepção do Processo } \\
\text { de Ensino e } \\
\text { aprendizagem mediado } \\
\text { pelas TDIC }\end{array}$ & \multicolumn{1}{|c|}{ Perfil do Professor } & \multicolumn{1}{c|}{$\begin{array}{c}\text { Competências a serem } \\
\text { desenvolvidas nos professores } \\
\text { Capacidade para }\end{array}$} \\
\hline $\begin{array}{c}\text { Centrada na dimensão } \\
\text { tecnológica. }\end{array}$ & Professor que domina as tecnologias. & $\begin{array}{l}\text { i. Valorizar e integrar as TDIC à } \\
\text { educação e ensinar seu uso no nível } \\
\text { técnico. } \\
\text { ii. Conhecer e utilizar softwares, } \\
\text { aplicativos, redes sociais em } \\
\text { contextos de prática profissional. } \\
\text { iii. Conhecer e dimensionar } \\
\text { implicações da utilização das TDIC } \\
\text { na vida cotidiana. }\end{array}$ \\
\hline $\begin{array}{l}\text { Centrada no acesso, } \\
\text { compreensão e produção } \\
\text { da informação. }\end{array}$ & $\begin{array}{l}\text { Professor que incentiva uma postura } \\
\text { crítica, por parte do discente, diante do do } \\
\text { material }\end{array}$ & $\begin{array}{l}\text { i. Interceder no processo de busca de } \\
\text { informações na rede. } \\
\text { ii. Obter, procurar, consultar }\end{array}$ \\
\hline
\end{tabular}




\begin{tabular}{|c|c|c|}
\hline & acessado/pesquisado/encontrado/elaborado. & $\begin{array}{l}\text { gerenciar, armazenar informações } \\
\text { novas e a criticidade diante delas, } \\
\text { utilizando as TDIC. } \\
\text { iii. Explorar as possibilidades de } \\
\text { acesso à informação visando } \\
\text { aprendizagem com TDIC. } \\
\text { iv. Ler, navegar, compreender, } \\
\text { postar, comentar, interagir e produzir } \\
\text { diversas linguagens } \\
\text { (hipermidiáticas). } \\
\text { v. Reconhecer riscos de segregação e } \\
\text { exclusão social, cultura do ódio, fake } \\
\text { news, que podem ser provocados } \\
\text { pelas TDIC, em função das } \\
\text { diferenças de acesso e do uso } \\
\text { desigual delas. }\end{array}$ \\
\hline $\begin{array}{l}\text { Centrada na construção } \\
\text { do conhecimento. }\end{array}$ & $\begin{array}{l}\text { Professor mediador, que acompanha o } \\
\text { processo de aprendizagem do discente, } \\
\text { mantendo diferentes graus de } \\
\text { envolvimento nele, cedendo o controle do } \\
\text { ensino-aprendizagem ao educando e } \\
\text { utilizando a tecnologia digital para criar } \\
\text { atividades que tenham como resultado a } \\
\text { reorganização de suas funções cognitivas. }\end{array}$ & $\begin{array}{l}\text { i. Elaborar e propor atividades com } \\
\text { base em problemas reais, reflexivas, } \\
\text { individuais e coletivas, construtivas, } \\
\text { adequada para que o discente } \\
\text { apreenda. } \\
\text { ii. Projetar processos de monitoria e } \\
\text { consulta, centrados no apoio ao } \\
\text { discente. } \\
\text { iii. Comunicar para promover a } \\
\text { aprendizagem estratégica } \\
\text { autorregulada. } \\
\text { iv. Garantir o acesso, o envolvimento } \\
\text { do discente e a continuidade do } \\
\text { envolvimento no processo de } \\
\text { aprendizagem. } \\
\text { v. Promover o uso das TDIC como } \\
\text { mais um meio de ensino- } \\
\text { aprendizagem. }\end{array}$ \\
\hline $\begin{array}{ll}\text { Centrada } & \text { em } \\
\text { metodologias ativas } & \end{array}$ & $\begin{array}{l}\text { Professor "Designer" de propostas de } \\
\text { aprendizagem, aquele que contempla todas } \\
\text { as competências, elencadas nas demais } \\
\text { concepções no seu agir pedagógico, em } \\
\text { parceria com os demais agentes (docentes, } \\
\text { discentes e escola). }\end{array}$ & $\begin{array}{l}\text { Todas as citadas e, ainda: } \\
\text { i. Compartilhar conhecimentos, } \\
\text { habilidades, emoções, atitudes e } \\
\text { valores. } \\
\text { ii. Compreender, analisar, propor, } \\
\text { desenvolver e avaliar, conforme o } \\
\text { que propõem as metodologias ativas. }\end{array}$ \\
\hline
\end{tabular}

Fonte: Caiado (2011)

Defendemos que todas as concepções do processo de ensino e aprendizagem mediadas pelas TDIC são necessárias para dar conta das práticas sociais de uso dos sujeitos e dos desafios que a nova sociedade digital nos impõe. Desta forma, ampliam-se as competências a serem desenvolvidas durante a formação deste professor nas instituições de ensino superior (IES); e, consequentemente, altera-se o seu perfil que, para mediar o processo de ensino e aprendizagem, necessita experienciar as tecnologias digitais da informação e comunicação, percorrendo, muitas vezes, os caminhos propostos aos estudantes, sem preconceitos, orientando e deixando-se orientar por eles em uma relação interativa ininterrupta. 
Outros autores referem-se a esse docente como $e$-mediador em quatro âmbitos: o pedagógico (desenvolvimento de um processo de aprendizagem virtual eficaz); o social (desenvolvimento de um ambiente de aprendizagem com um clima emocional e afetivo); o de organização e gestão (projeto instrucional adequado); o técnico (ajudar os estudantes a se sentirem confortáveis com os recursos e ferramentas que configuram a proposta instrucional) (MAURI; ONRUBIA, 2010).

A apresentação da experiência pedagógica a seguir, a saber: produção de textos imagéticos desenvolvida em tecnologia digital móvel, proposta para licenciandos em Letras, corrobora a relevância e urgência do trabalho com as metodologias ativas na escola em favor de um novo paradigma educacional que revisite o papel de docentes e discentes, incorporando o mobile learning/aprendizagem móvel e novas competências docentes, especificamente, no ensino e na aprendizagem de Língua Portuguesa.

\section{Metodologia}

A experiência pedagógica de produção de textos imagéticos em tecnologia digital móvel proporcionada para professores em formação inicial foi realizada com 15 discentes, do último período do Curso de Letras, no segundo semestre de 2018, de uma instituição de ensino superior de Recife. Este trabalho foi respaldado nas metodologias ativas com enfoque na aprendizagem baseada em projetos. $\mathrm{Na}$ busca pela formação de professores em um novo paradigma e revisão de práticas pedagógicas que permitam uma educação transformadora e colaborativa, propusemos aos discentes um projeto com foco na produção textual imagética realizada em tecnologia digital móvel: construir um texto totalmente imagético, com os recursos visuais presentes no aplicativo WhatsApp (WA), no smartphone, a partir do gênero textual fábula (O leão e o ratinho; A raposa e as uvas) ou do gênero textual conto de fadas (Chapeuzinho Vermelho; Os três Porquinhos ou Pinóquio), sugeridos pelo docente proponente da atividade.

A partir da experiência da Aprendizagem Baseada em Projetos - ABP, os discentes reuniram-se em pequenos grupos para fomentar a aprendizagem colaborativa e solucionar o desafio apresentado: produzir textos coerentes e coesos utilizando, exclusivamente, os recursos imagéticos do teclado do aplicativo $W A$. Diante disso, planejaram os passos para execução da tarefa. 
Em relação aos procedimentos adotados, os discentes foram motivados a: 1) escolher o gênero textual (fábula ou conto de fadas) e o conteúdo temático a ser trabalhado a partir do gênero escolhido; 2) identificar as características formais, funcionais, de conteúdo temático e estilo dos gêneros envolvidos: fábula ou conto de fadas; 3) ler, compreender e sintetizar os fatos principais presentes no gênero textual escolhido; 4) selecionar as imagens presentes no teclado do aplicativo $W A$ que tivessem relação com o conteúdo temático da fábula ou do conto de fadas, para a produção do texto imagético; 5) tomar decisões cooperativamente sobre como produzir um texto imagético, refletindo sobre os critérios da textualidade - coerência e coesão; 6) produzir o texto imagético em Tecnologia Digital Móvel - TDM; 7) socializar os textos imagéticos produzidos com a turma do $4^{\circ}$ período do curso de Letras, na disciplina Semântica da Língua Portuguesa, objetivando discutir recursos coesivos imagéticos presentes no texto relacionados à coerência; 8) relatar, minuciosamente, a discussão, a reflexão e o processo de construção do texto imagético nas disciplinas Laboratório de Língua Portuguesa e Literatura e Multiletramentos na Escola, fornecendo dados reais para as docentes pesquisadoras.

\section{Relato de experiência: uma análise}

Para este relato de experiência, selecionamos o trabalho de uma das equipes, composta por três professores em formação (doravante Equipe de Professores em Formação - EPF), utilizando como critério os argumentos apresentados em relação aos recursos coesivos utilizados para a construção de um texto imagético coerente. O gênero textual escolhido pela equipe foi a fábula "O leão e o ratinho", de autoria de Esopo, reproduzida a seguir de duas formas: linguagem verbal escrita e linguagem visual/ imagética.

\section{Quadro 2 - Fábula O Leão e o Ratinho}

\section{O Leão e o Ratinho}

Esopo

O Leão estava dormindo um bom sono, quando foi acordado por um rato que passou correndo em seu rosto. Agilmente, o mesmo o agarrou, e estava pronto para matá-lo.

Logo, o rato implorou:

- Por favor, solte-me, tenho certeza de que um dia irei poder retribuir este favor.

Logo, o Leão soltou com grandes risadas, pois um grande e forte destemido, não iria precisar de um rato.

Logo após um tempo, o Leão caiu em uma armadilha de caçadores. Estava preso e mal podia se mexer.

RIAEE - Revista Ibero-Americana de Estudos em Educação, Araraquara, v. 16, n. 4, p. 2682-2700, out./dez. 2021. e-ISSN: 1982-5587 
O Rato ao ouvir seus rugidos, roeu a corda até soltá-lo e disse:

- O senhor riu da ideia de que eu jamais iria poder lhe ajudar. Nunca pensou que poderia precisar de um pobre e pequeno rato!

Mas, agora, sabe que um pequeno Rato pode retribuir um favor a um grande Leão!

Moral da história: "Os pequenos amigos podem se revelar os melhores e mais leais aliados".

Fonte: Esopo 550 a.C. (2011, p. 154)

Figura 1 - Produção Imagética em TDM: O Leão e o Ratinho

Fonte: Produção elaborada por discentes do último período do curso de Letras 
Especificamente neste relato de experiência, a equipe compartilha, colaborativamente, o processo de construção do texto imagético, a partir dos critérios já citados: coesão e coerência, e da autonomia propiciada pelo uso de metodologias ativas no processo de ensino e aprendizagem de Língua Portuguesa, fazendo com que os professores em formação se autoorganizem, a partir da construção personalizada do conhecimento; gerenciem o conteúdo em tempo-espaço e assumam a posição de autores de desafios e mediadores do conhecimento, simultaneamente, capazes de criar teias textuais imagéticas harmoniosas para a produção de sentidos. Dividimos o relato da experiência pedagógica vivenciada pela equipe selecionada em cinco fragmentos que passamos a analisar, respeitando a maneira como foi escrito pela EPF.

\section{Quadro 3 - Fragmento 1}

EPF: Antes de iniciarmos a produção no Whatsapp, foi realizada a leitura da fábula "O leão e o ratinho", a fim de que se compreendesse o texto.

Fonte: Elaborado pelas autoras

Em relação ao conhecimento compartilhado pela EPF, no fragmento 1, tecemos as seguintes considerações: é de fundamental importância dentro da aprendizagem baseada em projetos, inserida nas metodologias ativas, que o docente em formação identifique os objetivos do projeto em relação ao desafio proposto. Dessa forma, a primeira ação da equipe foi realizar uma leitura compreensiva da fábula escolhida, o que possibilitou identificar as ideias centrais do texto, de forma a ressignificar e a reelaborar a fábula no formato imagético.

Quadro 4 - Fragmento 2

EPF: O segundo passo realizado para a produção consistiu em discutir com o grupo sobre como os emojis do WhatApp têm o potencial de significação. Neste momento, chegamos à conclusão de que eles podem ser compreendidos de diversas maneiras. O melhor modo, de acordo com nosso critério, foi de utilizar apenas um emoji como elemento de significação. Portanto, cada emoji utilizado na produção imagética corresponde a uma palavra ou uma ideia central.

Fonte: Elaborado pelas autoras 
No fragmento 2, que se refere ao segundo passo realizado pela equipe, a orientação do docente propositor do projeto foi que o grupo selecionasse emojis relacionados ao texto escolhido. A equipe iniciou a busca por imagens ou referências visuais que dessem pistas para identificar o conteúdo temático da produção textual. Na fábula, a pista semântica é centrada no título: imagem do leão e imagem do ratinho, que a depender do conhecimento prévio dos sujeitos, levaria à descoberta da fábula "O leão e o ratinho".

Neste sentido, os professores em formação apresentaram a concepção de ensino e aprendizagem centrada na construção do conhecimento, o que possibilitou a reflexão do potencial de significação dos emojis disponíveis no teclado relacionados à fábula "O leão e o ratinho", ou seja, eles não se restringiram, apenas, à seleção dos emojis, tomando uma atitude autônoma neste processo em relação à orientação recebida.

\section{Quadro 5 - Fragmento 3}

EPF: Ao iniciar a produção, um questionamento surgiu: De que maneira deixar a produção com uma sequência lógica (coerente) de modo que ela esteja bem articulada (coesa)? O recurso que utilizamos para satisfazer ao questionamento foi utilizar os espaços entrelinhas como marcadores sequenciais. Outros recursos utilizados para tornar o texto imagético mais compreensível foi estabelecer relações de sinonímia e antonímia entre os emojis, como o ícone de um cadeado aberto e outro fechado para passar a ideia de preso/prendeu e solta/soltou; marcar no início de cada linha (sequência), o personagem que fala, pois assim é possível que se identifique mais rapidamente o autor da ação ou da fala.

Fonte: Elaborado pelas autoras

O fragmento 3 pode ser analisado como uma autorreflexão da equipe de professores em formação, que objetivava procurar soluções para o desafio proposto, sendo capazes de propor atividades com base em problemas reais, que requeiram reflexão, construção individual e coletiva construtiva.

A solução encontrada pela equipe reforça o que Caiado, Fonte e Barros (2018) e Fonte, Barros e Caiado (2019) denominaram de coesão do tipo “conexão por contiguidade temporal e/ou espacial", pois os espaços entre as linhas seriam marcadores sequenciais, funcionando como recurso coesivo para o texto imagético. Outro recurso utilizado pela equipe para tornar o texto imagético mais compreensível foi o estabelecimento de sinonímia e antonímia ${ }^{9}$ entre as imagens, emojis, ou seja, a EPF demonstrou capacidade de gestão, envolvimento e controle do processo de aprendizagem, auxiliado pelas TDM, compreendida neste processo enquanto mais um meio de ensino e aprendizagem.

9 “A sinonímia pode ter duas acepções diferentes: ou dois termos são ditos sinônimos quando têm a possibilidade de se substituírem um ao outro num único enunciado isolado [...], ou os dois termos são ditos sinônimos (sinonímia absoluta) quando são intercambiáveis em todos os contextos [...].” (DUBOIS et al, 1973, p. 555); “Os 


\section{Quadro 6 - Fragmento 4}

EPF: Por fim, chegamos também a algumas conclusões empíricas. A primeira é a que a voz passiva, se for transposta para o texto imagético, pode causar uma confusão semântica. Curiosamente, em textos escritos verbais, a voz passiva altera a posição do sujeito.

Fonte: Elaborado pelas autoras

$O$ relato contido no fragmento 4 demonstra que a EPF intercedeu no processo, procurou, consultou, desenvolveu postura autônoma ao explorar as possibilidades de reelaboração da fábula, demonstrando uma concepção do processo de ensino e aprendizagem centrada no acesso, compreensão e produção da informação. Para garantir a coerência do texto imagético, os professores em formação alteraram a voz do sujeito paciente-agente, ou seja, da voz passiva reelaboraram o texto para a voz ativa, inserindo a imagem dos emojis dos personagens da fábula, marcando a troca de turnos e o próprio enunciador do discurso.

\section{Quadro 7 - Fragmento 5}

EPF: A outra conclusão é que, embora haja diversos emojis no WhatsApp, eles ainda são limitados, em alguns casos, como no da palavra "armadilha". Para passar essa ideia, utilizamos a imagem de "espirais".

Fonte: Elaborado pelas autoras

No fragmento 5 podemos refletir sobre toda a riqueza da concepção centrada em metodologias ativas, e na ABP, pois deparamo-nos, no relato, com professores "designers" de propostas, também alternativas para o desafio proposto.

A EPF, diante da limitação dos emojis apropriados para dar significação ao texto imagético, realizou uma "associação coesiva"10 para estabelecer a ideia de "armadilha", selecionando uma imagem em "espiral", estabelecendo, dessa maneira, uma relação semântica entre a ideia de "armadilha" e a imagem de "espiral", conforme propõem Caiado, Fonte e Barros (2018) e Fonte, Barros e Caiado (2019).

Neste sentido, consideramos que a equipe compreendeu, analisou e propôs uma alternativa para a dificuldade, capacidade centrada na ABP.

antônimos são unidades de sentidos contrários; essa noção de 'contrário' define-se em geral em relação a termos vizinhos, os complementares [...] e os recíprocos” (DUBOIS et al., 1973, p. 56-57).

${ }^{10}$ A associação coesiva representa a relação semântica das imagens com as ideias que elas sugerem (CAIADO; FONTE; BARROS, 2018). 


\section{Considerações finais}

Este artigo apresentou o relato de uma experiência pedagógica - produção de textos imagéticos - desenvolvida em Tecnologia Digital Móvel (TDM), a partir da aprendizagem baseada em projetos, proposta para professores em formação.

Metaforicamente, podemos inferir a relação de ensino e aprendizagem a partir das palavras homófonas ${ }^{11}$ : “Agente"/“a gente”. A primeira remete ao sentido daquele que atua ou age sobre algo; a segunda revela o sentido coletivo de nós. Percebemos o processo de ensino e aprendizagem, na educação contemporânea, considerando os sujeitos protagonistas que agem coletivamente, permeados pelas metodologias ativas de ensino, exigindo que docentes, discentes e a escola tornem-se operadores colaborativos e coparticipantes na construção do conhecimento.

Observamos que o processo de ensino e aprendizagem mediado pela TDIC, inserido na concepção das metodologias ativas, conclama o docente a desenvolver novas competências relacionadas ao papel de "designer" de propostas de aprendizagem, isto é, que ele saiba, diante de cada novo cenário, criar e recriar conceitos e comportamentos em seu agir pedagógico, compartilhando, colaborativamente, conhecimentos, habilidades, atitudes, valores e emoções com seus discentes.

Após a experiência pedagógica - produção de textos imagéticos - desenvolvida em Tecnologia Digital Móvel (TDM), a partir da aprendizagem baseada em projetos, proposta para professores em formação, percebemos que, ainda, existe resistência e ausência de práticas que enfoquem a imagem trabalhada em diferentes eixos de ensino (no caso deste relato de experiência, no eixo produção textual), e em diferentes contextos sociais; consequentemente, o enfoque no letramento visual, necessário à compreensão e à elaboração dos textos imagéticos presentes em plataformas e dispositivos digitais, fica prejudicado ou relegado a segundo plano em algumas instituições de ensino.

Durante a solução do desafio proposto aos discentes, identificamos que os emojis do smartphone ocupam o lugar dos signos linguísticos em textos imagéticos, uma vez que o significado das imagens não esteve atrelado a um único significante. Quando não havia uma imagem que retratasse tão explicitamente a ideia do grupo, outro significante imagético assumiu seu lugar, sendo os novos signos tomados e aceitos pelo pequeno grupo social participante do projeto.

11 "Homofonia é a identidade fônica entre duas ou mais unidades significativas, ou entre dois ou mais signos gráficos” (DUBOIS et al., 1973, p. 326). 
As maiores dificuldades encontradas pelo grupo localizaram-se no estabelecimento da coesão e da coerência textual para atender à passagem de tempo verbal e, em virtude das restrições imagéticas presentes no teclado do aplicativo WhatsApp, os discentes precisaram efetuar associações semânticas que garantissem a coerência do texto.

Finalmente, concluímos que os docentes em formação ampliam e desenvolvem novas competências quando utilizam caminhos autônomos que os façam avançar em conhecimento, competências socioemocionais e em novos gestos pedagógicos.

\section{REFERÊNCIAS}

ALMEIDA, D. Multimodalidade e ensino: integrando o texto e o contexto em estruturas visuais. In: BARBARA, L.; MOYANO, E. (org.). Textos e linguagem acadêmica: explorações sistêmico funcionais em espanhol e português. Campinas: Mercado de letras, 2011. p. 55-66.

BALACHEFF, N. La transposition informatique. Note sur um nouveau problème pour la didactique. In: ARTIGUE, M. et al. Vingt ans de didactique des mathématiques en France. Grenoble: La Pensée Sauvage Editions, 1994. p. 364-370.

BENDER, W. N. Aprendizagem baseada em projetos, educação diferenciada para o século XXI. Porto Alegre: Penso, 2015.

BONILLA, M. H. Escola Aprendente: para além da sociedade da informação. Rio de Janeiro: Quartet, 2005.

BRANSFORD, J. D.; BROWN, A. L.; COCKING, R. R. How people learn: brain, mind, experience, and school. Washington, D.C.: National Academy Press, 2000.

CAIADO, R. Novas tecnologias digitais da informação e comunicação e o ensinoaprendizagem de Língua Portuguesa. Tese (Doutorado em Educação) - Universidade Federal de Pernambuco, Recife, 2011. Disponível em:

https://repositorio.ufpe.br/handle/123456789/3900. Acesso em: 15 ago. 2020.

CAIADO, R.; FONTE, R.; BARROS, I. Textualidade em tecnologia digital móvel: a construção da coesão e da coerência em textos imagéticos. Hipertextus Revista Digital, Recife, v. 19, p 23-38, 2018. Disponível em:

http://www.hipertextus.net/volume19/Art2Vol19.pdf. Acesso em: 10 ago. 2019.

CAIADO, R.; LEFFA, V. J. A oralidade em tecnologia digital móvel: debate regrado via WhatsApp. Hipertextus Revista Digital, Recife, v. 16, n. 1, p. 109-133, 2017. Disponível em: https://periodicos.ufpe.br/revistas/hipertextus/article/view/247924. Acesso em: 10 ago. 2019.

CUNHA, C. S. et al. Aprendizagem baseada em projetos: definições e aplicabilidades. In: NEVES, V. J. et al. (org.). Metodologias ativas: inovações educacionais no ensino superior. Campinas: Pontes Editores, 2019. p. 93-104. 
DUBOIS, J. et al. Dicionário de linguística. São Paulo: Cultrix, 1973.

ESOPO 550 a.C. Fábulas de Esopo. Porto Alegre: L\&PM, 2011.

FONTE, R.; BARROS, I.; CAIADO, R. A coesão e a coerência em tecnologia digital móvel: produção textual da fábula imagética. In: CAIADO, R.; BARROS, I.; BEZERRA, B. (org.) Linguagem interdisciplinaridade: diferentes gestos de interpretação. São Paulo: Pá da Palavra, 2019. p. 35-47.

FREIRE, P. Pedagogia da autonomia: saberes necessários à prática educativa. São Paulo: Paz e Terra, 2011.

KRAJCIK, J.; BLUMENFELD, P. Project-Based Learning. In: SAWYER, R. (Ed.). The Cambridge Handbook of the Learning Sciences. Cambridge: Cambridge University Press, 2005. p. 317-334.

MAURI, T.; ONRUBIA, J. O professor em ambientes virtuais: perfil, condições e competências. In: COLL, C.; MONEREO, C. (org.). Psicologia da Educação Virtual: aprender e ensinar com as tecnologias da informação e da comunicação. Porto Alegre: Artmed, 2010. p. 118-135.

MORAN, J. Metodologias ativas para uma aprendizagem mais profunda. In: BACICH, L.; MORAN, J.(org.) Metodologias Ativas para uma educação inovadora: uma abordagem teórico-prática. Porto Alegre: Penso, 2018. p. 1- 44.

PÉREZ GÓMEZ, Á. I. Educação na Era Digital: a Escola Educativa. Trad. Marisa Guedes; Rev. técnica Bartira Costa Neves. Porto Alegre: Penso, 2015.

VALENTE, J.; ALMEIDA, M. E. Narrativas digitais e o estudo de contextos de aprendizagem. Revista em Rede, Porto Alegre, v. 1, n. 1, p. 32-50, 2014. Disponível em: https://www.aunirede.org.br/revista/index.php/emrede/article/view/10. Acesso em: 13 ago. 2019.

XAVIER, A. C. Letramento digital e ensino. In: SANTOS, C. F.; MENDONÇA, M. (org.). Alfabetização e Letramento: conceitos e relações. Belo Horizonte: Autêntica, 2005. p. 133148. 


\section{Como referenciar este artigo}

CAIADO, R.; FONTE, R. F. L.; BARROS, I. B. R. Metodologias ativas e novas competências docentes: uma experiência de produção de textos imagéticos no meio digital. Revista Ibero-Americana de Estudos em Educação, Araraquara, v. 16, n. 4, p. 2682-2700, out./dez. 2021. e-ISSN: 1982-5587. DOI: https://doi.org/10.21723/riaee.v16i4.14043

Submetido em: 16/07/2021

Revisões requeridas em: 15/08/2021

Aprovado em: 12/09/2021

Publicado em: 21/10/2021 